\title{
Novos Cadernos NAEA
}

v. 9 , n. 2 , p. 5-24, dez. 2006, ISSN 1516-6481

\section{A mão-de-obra da indústria pesqueira na Amazônia}

Lucilene Amaral - Pesquisadora do Instituto de Pesquisa Ambiental da Amazônia IPAM.

Oriana Almeida - Prof ${ }^{a}$. do Núcleo de Altos Estudos Amazônicos da UFPA.

Sérgio Rivero - Prof. do Departamento de Economia da UFPA.

\section{Resumo}

O setor pesqueiro tem grande importância em termos de geração de emprego e renda para a Amazônia, sendo a atividade de pesca comercial e de subsistência a maior fonte geradora de empregos do setor e a indústria pesqueira a grande fonte geradora de renda. Contudo, a indústria pesqueira na Amazônia apresenta diversas dificuldades em relação ao abastecimento de matéria-prima e treinamento da mão-deobra. A sazonalidade das espécies influencia o sistema produtivo das empresas que mantém seu quadro funcional variando devido a safra das espécies comerciais. Esta dinâmica do setor faz com que algumas empresas de pescado adotem sistemas rotativos, contratando funcionários na safra e demitindo-os na entressafra, enquanto que outras adotam o sistema de banco de horas, mantendo o quadro fixo de funcionários e compensando as horas trabalhadas a mais no período da safra por horas não trabalhadas no período da entressafra. Em razão desta sazonalidade, em geral, as empresas de pescado apresentam funcionários com baixa qualificação e com difícil adequação aos padrões de higiene. A instabilidade do emprego por outro lado, desestimula o funcionário ao treinamento. Manter o quadro fixo de empregados é política de algumas empresas. Essas apresentam menor desperdício de matéria-prima, maior rendimento do empregado, funcionários mais treinados e adaptados aos padrões de higiene exigidos. Contudo, a contratação de empregados permanentes exige que a empresa tenha uma estratégia mais ampla para o abastecimento de pescado na entressafra de forma que seja possível manter a mão-de-obra contratada nesse período.

\section{Palavras-chave}

Amazônia, Industria pesqueira.

\section{Abstract}

Fishery is a very important sector in the Amazon area. Commercial and subsistence fishing activities account for the main job opportunities in the sector, and fishing industries are the greatest income generators for the local population. The fishing industry in Amazon, however, struggles with several difficulties regarding raw-material and training. The seasonality of the species affects the production systems of the companies, which, in their turn, must shift their staff according to the commercial species. Because of this dynamics, some fishing companies use a rotation system, hiring during the harvest season and firing during the period between harvests; other companies use a working load system, keeping a steady staff and making up for the extra working hours during harvest by granting non working hours during the period between harvests. In general, due to this seasonality, fishing companies staff are low qualified and have lower hygiene standards. Uncertainty in keeping jobs, on the other hand, does not motivate employees to training. Some companies policy include keeping a steady staff. Such companies waste less raw material and their employees are better trained and are adapted to higher hygiene standards. In order to maintain a steady staff, these companies must develop a broader fishing strategy during the period between harvests.

\section{Keywords}

Amazon, Fishing industry. 
Lucilene Amaral / Oriana Almeida / Sérgio Rivero

\section{INTRODUÇÃO}

A pesca na Amazônia, é uma das principais atividades da região de várzea (Almeida et al. 2001, MCGRATH et al. 2003; RUFFINO, 2001; BATISTA, 1998; BAYLEY e PETRERE, 1989; BARTHEM, 1999, McGrath et al. 1998, Oliveira e Cunha 2000, Smith 2000). Na estimativa de Almeida et al. (2004) o número de pescadores de subsistência foi estimado em 112.000 e o número de pescadores comerciais em 48.000 considerando somente a calha Amazonas-Solimões. Em termos de emprego e renda, as atividades da pesca de subsistência e comercial representam a maior fonte de geração de emprego do setor (66 e 29\%, respectivamente), enquanto a indústria se mostrou como uma importante fonte de renda (36\%) (ALMEIDA et al., 2004; Cabral et al. 2006, Almeida e Almeida 2006). Mesmo assim a indústria emprega mais de 4000 pessoas nos frigoríficos do estado do Amazonas e Solimões.

A indústria pesqueira enfrenta vários problemas. Os principais são o abastecimento da matéria-prima (Almeida e Almeida 2006) e a dificuldade de treinamento de mão-de-obra. As dificuldades com a mãode-obra estão relacionadas com a qualificação e a sazonalidade do trabalho, por causa da safra de pescado. Em virtude do comportamento sazonal das espécies, sua disponibilidade é variável durante o ano. O sistema produtivo da empresa é, portanto, regulado pela oferta de pescado, o que resulta também na sazonalidade do emprego da mãode-obra. Essa dinâmica faz com que as empresas contratem inúmeros funcionários durante a safra e depois os delimitam, o que gera alta rotatividade no setor e um problema crônico de qualificação de mão-deobra (Cabral e Almeida 2006, Almeida e Almeida 2006, Sena 2006).

A maior parte dos estudos sobre a mão-de-obra em barcos da pesca artesanal abordam o assunto de forma muito sintética, estimando o número de pessoas empregadas no setor. Poucos examinam a questão da mão-de-obra na indústria. O objetivo deste trabalho é caracterizar o trabalho da mão-de-obra na indústria pesqueira e avaliar o impacto da sazonalidade da pesca na mão-de-obra da indústria pesqueira do Pará e do Amazonas.

\section{A INDÚSTRIA DE PESCADO}

O estado do Amazonas e Pará são, atualmente, os dois estados mais importantes em relação à produção da pesca continental no Brasil correspondendo a 26,1 e 10,5\% da captura total brasileira (Ibama 2000, 
Cabral et al. 2006). A indústria de pescado se desenvolveu principalmente no estado do Pará a partir dos incentivos fiscais da década de 70. No estado do Pará as empresas processam uma média de 2.565 toneladas por ano somando um total de processamento de 30.778 toneladas/ano. No estado do Amazonas esses valores são bem menores. Em geral as empresas são de menor porte processando uma média de 550 toneladas somando um total de 6.600 toneladas/ano. No estado do Pará 70\% desse valor é exportado para outros estados do Brasil, 20\% para o exterior e o restante consumido dentro do próprio estado. No amazonas, 60\% é exportado para outros estados do Brasil, 34\% para o exterior e o restante consumido localmente (Cabral et al. 2006).

Considerando as exportações desses dois estados, do volume total exportado pelo estado do Pará em torno de 43\% refere-se à exportação de camarão e lagosta, 35\% relativo a peixe inteiro e $11 \%$ a filé, somando $89 \%$ e 3\% relativo a peixes ornamentais. Durante os últimos 6 anos peixes ornamentais tem representado entre 7 e 9\% na maior parte dos anos tendo somente em 2004 e 2006 respondido por 20 e 29\% da exportação, respectivamente.

No Amazonas a exportação de peixes ornamentais é grande em relação à exportação de pescado. Durante os últimos seis anos peixes ornamentais representaram de 75 a 100\% do volume total de exportação. Peixe inteiro em geral representou entre zero e 4\% das exportações para fora do Brasil tendo somente em 2002 e 2006 apresentando valores acima de 13\%. )(Tabela 1).

A indústria de pescado tem sido responsável pela geração de $36 \%$ da renda do pescado (Almeida et al. 2004) e processado um importante volume do pescado da região. É um setor que consome grande parte do pescado e portanto, seu conhecimento é muito importante para a gestão do recurso pesqueiro. A sazonalidade das espécies abastecem os frigoríficos de maneira irregular ao longo do ano gerando, por conseqüência, uma sazonalidade no emprego da mão de obra dentro das fábricas que é importante de se entendida. 


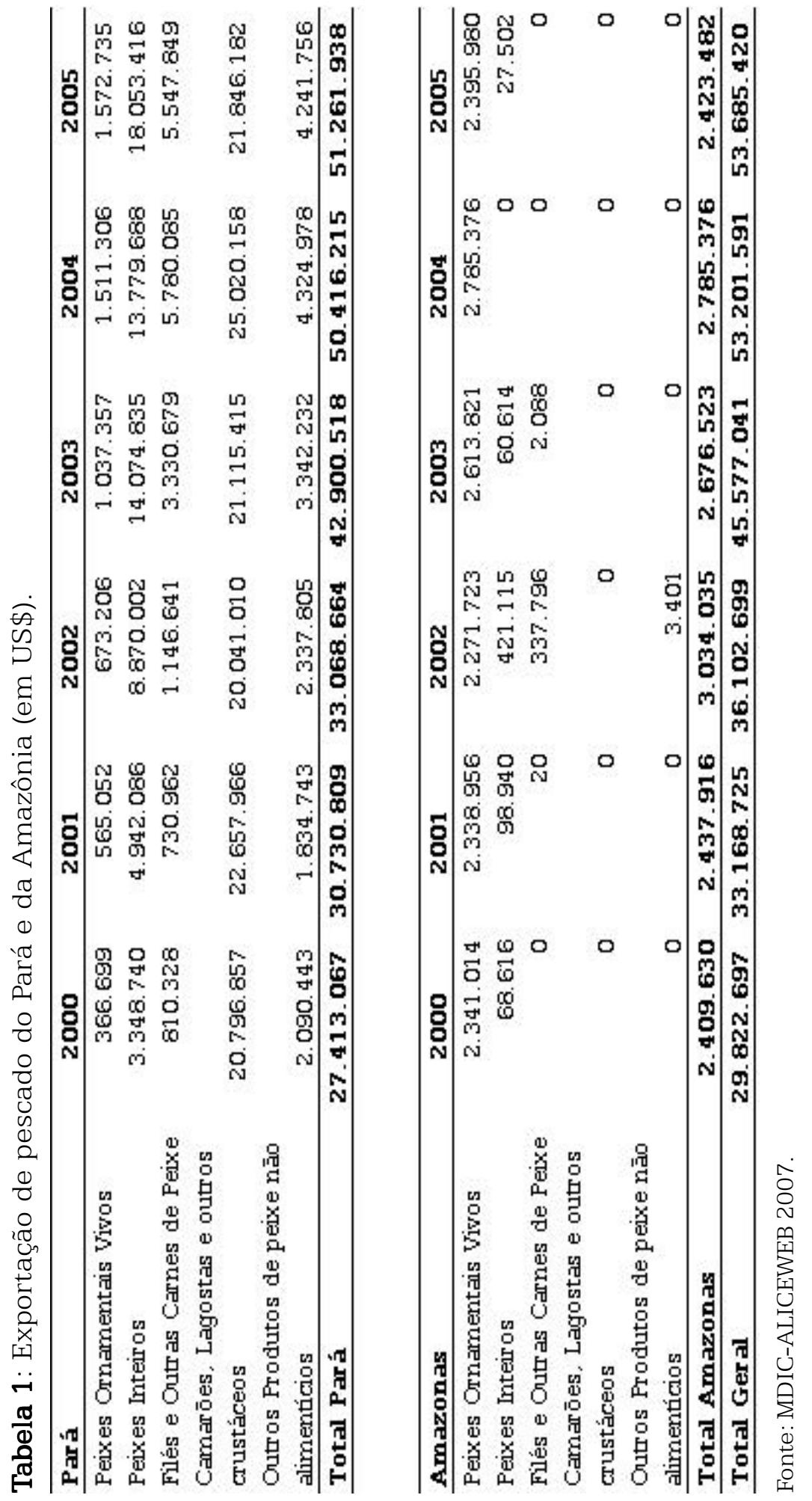




\section{Metodologia}

Os trabalhos de pesquisa foram executados nos estados do Pará e do Amazonas em frigoríficos da região de abrangência do estudo: Belém, Santarém, Manaus, onde está localizada a maior parte das empresas. A pesquisa foi feita em 18 frigoríficos em outubro e novembro de 2002; foram realizadas entrevistas com os funcionários das empresas em agosto e setembro de 2003.

As empresas foram convidadas a participar da pesquisa por intermédio da Associação da Indústria Pesqueira do Pará e do Amazonas. As empresas em que foram realizadas as entrevistas aceitaram que o trabalho fosse realizado nas suas indústrias. Na cidade de Santarém, o contato foi feito diretamente com as empresas que aceitaram participar da pesquisa.

Foram visitadas 9 empresas de pescado, e foram entrevistados aproximadamente $25 \%$ dos empregados de cada empresa, o que resultou num total de 185 entrevistas com os funcionários. As entrevistas foram feitas com funcionários da administração e da produção. O total de funcionários foi dividido em produção e administração, e a quantidade entrevistada foi proporcional ao número total de funcionários em cada uma dessas áreas (administração $(n=23)$, produção $(n=162)$ e setor de manutenção de máquinas e limpeza $(n=30))$.

\section{A mão-de-obra e a empresa}

As empresas de pescado podem adotar duas condutas distintas em relação ao quadro de funcionários. Algumas seguem o sistema rotativo, ou seja, contratam funcionários temporários para o período da safra, demitindo-os na entressafra. Outras trabalham com mão-de-obra permanente e utilizam o sistema de banco de horas para compensar entre safra e entressafra. Das empresas entrevistadas, 56\% não utilizam mão-de-obra temporária.

Durante a safra, a média de funcionários contratados é de 99 pessoas por empresa, enquanto na entressafra a média é de 34 funcionários. A média na entressafra é baixa, porque há três empresas que praticamente fecham durante esse período. As empresas de pescado possuem em média 68 funcionários na produção (incluindo o setor de embalagem), dez no setor de manutenção de máquinas e limpeza e o restante na administração (Tabela 2). 
Lucilene Amaral / Oriana Almeida / Sérgio Rivero

Tabela 2: Número de funcionários das empresas de pescado dos estados do Pará e do Amazonas.

\begin{tabular}{lc}
\hline \multicolumn{1}{c}{ Número de funcionários } & Média \\
\hline Número de funcionários da produção & 68 \\
Número de funcionários da marutenção & 10 \\
Média de funcionários (safra) & 99 \\
Média de funcionários (entressafra) & 34 \\
\hline
\end{tabular}

O setor de produção agrupa 70\% dos funcionários, que exercem funções em três áreas: recepção do pescado, beneficiamento e embalagem. Na recepção, é feita a análise sensorial do pescado (aspecto, cheiro e consistência), para verificar se está propício para o consumo, e o acondicionamento no gelo é examinado. Os balanceiros, pessoas ligadas ao setor administrativo, também trabalham na recepção do pescado e ainda exercem a função de pesagem, além de efetuarem o pagamento aos fornecedores. No beneficiamento, os funcionários exercem as funções de desossadores, retirando as espinhas do pescado, de operadores de máquinas, retirando a pele do pescado, e de filetadores, preparando o filé. Algumas empresas também mantêm os empacotadores, que fazem a embalagem primária do pescado, ainda no setor da produção, para posterior congelamento e embalagem final.

\section{A mão-de-obra na perspectiva da empresa}

A sazonalidade das espécies influencia diretamente o abastecimento de matéria-prima e a contratação da mão-de-obra na indústria pesqueira. Mais da metade das empresas afirma ter dificuldades com mão-de-obra; 80\% desses problemas localizam-se na área da produção e somente $20 \%$, no setor administrativo. No que diz respeito à mão-de-obra, 53\% das empresas relatam problemas ligados à baixa qualificação e 25\%, à difícil adequação do funcionário ao padrão de higiene exigido.

Das indústrias visitadas, três funcionam somente no período de safra do pescado. Uma delas afirma que, no processo de recontratação, aproximadamente $40 \%$ dos empregados são os mesmos do ano anterior; a empresa não tem problemas para recrutar mão-de-obra, em função do crescente desemprego. Em geral, esses empregados são recrutados mediante um contrato temporário, no entanto, de acordo com as indústrias, os funcionários do setor de produção passam a ter a carteira de trabalho assinada após três meses de trabalho. 


\section{Benefícios oferecidos pela empresa}

Em geral, as indústrias de pescado oferecem aos seus funcionários, principalmente aos do setor de produção, alguns benefícios que não são exigidos pela Consolidação das Leis Trabalhistas (CLT), ainda que alguns direitos do trabalhador, como a assinatura da carteira de trabalho, não sejam observados de imediato. Os benefícios extras mais comuns são o almoço (67\% das empresas), o crédito em farmácia (67\% das empresas) e o seguro de vida (63\% das empresas). Outras ainda oferecem café da manhã (44\%), lanche (44\%), cesta básica uma vez por ano (22\%) e caixa de empréstimo pessoal (22\%). Uma iniciativa adotada em menor escala refere-se às atividades recreativas, como a utilização do sistema de ginástica laboral, que tende a aliviar a tensão provocada pelo ritmo intenso do trabalho e pelo tempo prolongado de trabalho em pé.

\section{Cursos oferecidos pela empresa}

As indústrias de pescado consideram muito importante o treinamento do funcionário e, geralmente, oferecem treinamento a seus funcionários. Em função desse treinamento, algumas empresas criaram auditórios para que os cursos sejam ministrados nas suas próprias dependências. Das empresas visitadas, 67\% oferecem cursos de treinamento destinados principalmente a funcionários da produção (média de 27 empregados por curso). Em 2003, foram organizados oito cursos de treinamento por seis empresas diferentes, o que significa que uma empresa realiza em média 1,3 treinamento por ano. Os principais cursos oferecidos são: Boas Práticas de Manipulação de Pescado (GMP) (39\%), Análise de Perigos e Pontos Críticos de Controle (APPCC) (23\%), Higienização e Sanitização (15\%) e Análise Sensorial de Pescado (15\%). 
Lucilene Amaral / Oriana Almeida / Sérgio Rivero

Tabela 3: Cursos de treinamento de pescado oferecidos pela indústria pesqueira, Pará e Amazonas.

\begin{tabular}{lr}
\hline Cursos de treinamento na empresa & \\
\hline Empresas que ofereceram cursos & $67 \%$ \\
Número de cursos oferecidos em 2003 & 8 \\
Média de participantes por curso & 27 \\
Participantes do setor de produção & $92 \%$ \\
Participantes da administração & $8 \%$ \\
Principais cursos oferecidos & \\
\hline Boas Práticas de Manipulação de Pescado (GMP) & $39 \%$ \\
APPCC & $23 \%$ \\
Higienização e Sanitização & $15 \%$ \\
Análise Sensorial de Pescado & $15 \%$ \\
Contabilidade & $8 \%$ \\
\hline
\end{tabular}

Empresas que participam do sistema de APPCC oferecem aos funcionários uma série de cursos, exigidos pelo controle de qualidade do Ministério da Agricultura para as empresas "sifadas". Empresas menores muitas vezes desenvolvem um sistema simples de treinamento da mão-de-obra. Para as que processam o pescado somente eviscerado, sem cabeça, o processamento consiste somente na decapitação e nalavagem do pescado. Nesse caso, o treinamento é feito pelo próprio encarregado da produção, que em uma semana treina todo o pessoal.

Adicionalmente, algumas empresas também implantaram o sistema de Telecurso 2000, em parceria com o Serviço Social da Indústria (SESI), para tentar diminuir o número de funcionários semi-analfabetos e elevar o grau de instrução. Com essa medida, as empresas preparam seus funcionários a fim de receberem as instruções dos treinamentos específicos para a linha de produção.

\section{Os trabalhadores nas indústrias de pescado}

Com base em 185 entrevistas feitas diretamente com funcionários, foi traçado o perfil da mão-de-obra do setor. A mão-de-obra nas indústrias de pesca foi classificada em três categorias distintas de acordo com as funções dentro da estrutura da empresa: funcionários do setor administrativo, do setor de produção e do setor de manutenção e limpeza. Dos funcionários da administração, 57\% são casados, 39\% são solteiros e $4 \%$ são separados ou divorciados. A religião predominante é a católica (86\%), os evangélicos somam 9\% e os espíritas, 5\%. Esse perfil, 
basicamente, não varia para os funcionários da produção e da manutenção, mantendo a mesma ordem de grandeza. O número de filhos dos funcionários das empresas de pescado também é semelhante nas três categorias de funções. Um funcionário tem em média três filhos, dos quais dois são menores de idade.

A maioria dos empregados das empresas de pescado é composta por mulheres, que assumem principalmente as funções nos setores de produção (65\%) e administração (78\%). Os serviços do setor de manutenção de máquinas são executados geralmente por homens, enquanto os serviços de limpeza são realizados por mulheres.

Um número razoável de funcionários da produção e da manutenção completou os quatro primeiros anos do ensino fundamental (27\% e 30\%), e aproximadamente três quartos completaram o ensino médio. No setor administrativo, o nível de escolaridade é mais alto: 70\% dos funcionários completaram o ensino médio.

\section{Caracterização econômica dos funcionários}

A renda mensal recebida pelo funcionário da produção é em torno de $\mathrm{R} \$ 315,00$. Nos casos em que mais algum membro da família trabalhe, a renda familiar total atinge aproximadamente $\mathrm{R} \$ 520,00$ mensais. A maior parte da renda familiar é destinada ao pagamento de despesas com alimentação (média de $\mathrm{R} \$ 180,00)$, aluguel (R\$ 73,00) e educação (R\$ 64,00).

A maior parte dos funcionários mora em casa própria (72\% e 81\%), onde residem em média mais quatro pessoas da família. Mais da metade dos funcionários da produção (64\%) e da manutenção (61\%) mora em casas de alvenaria, podendo ser próprias, alugadas ou de terceiros. Todas as casas contam com fornecimento de energia elétrica, no entanto, 27\% das residências não recebem abastecimento público de água.

Grande parte dos funcionários também possui eletrodomésticos. Dos funcionários do setor de produção e de manutenção, 76\% e 84\% têm geladeira, 95\% e 100\% têm fogão, 86\% e 97\% têm televisão, 65\% e $77 \%$ têm ventilador e $70 \%$ e $81 \%$ têm ferro elétrico, respectivamente. Entretanto, observa-se que 5\% dos funcionários da produção não possuem fogão, que é considerado um eletrodoméstico imprescindível atualmente na zona urbana.

Dos funcionários da administração, aproximadamente o mesmo percentual mora em casa própria. Somente uma proporção um pouco maior mora em casa feita de alvenaria, em média com mais cinco pessoas. A renda dos funcionários da administração é bem mais alta do que a 
Lucilene Amaral / Oriana Almeida / Sérgio Rivero

dos funcionários da produção e da manutenção, ficando em torno de R\$ 748,00 . Na unidade familiar, mais de uma pessoa trabalha e obtém renda, o que eleva a renda familiar para um total de $\mathrm{R} \$ 1.434,00$ mensais, em média. Todas as casas contam com fornecimento de energia elétrica. Em razão da renda familiar, os funcionários do setor administrativo podem investir bem mais em alimentação e educação do que os funcionários do setor de produção. Em geral, o funcionário da administração gasta duas vezes mais com alimentação e três vezes mais com educação do que o funcionário da produção.

\section{Histórico do trabalho dos funcionários}

As mulheres correspondem a $64 \%$ do total de funcionários das empresas. Metade das funcionárias dos setores de produção e manutenção começou a trabalhar somente aos 18 anos, como doméstica, babá ou cozinheira (41\%). Os homens do mesmo setor começaram a trabalhar mais cedo, a maioria (63\%) começou a trabalhar entre 10 e 18 anos. No caso dos homens, as ocupações iniciais variam bem mais do que as das mulheres: eles trabalham inicialmente como agricultores, vendedores, auxiliares de produção, mecânicos, eletricistas, pedreiros e em diversas outras atividades.

As empresas de processamento geralmente adotam regimes de trabalho diferentes dos ditados pela lei trabalhista, ainda que amparadas por acordos coletivos com o sindicato dos trabalhadores. Freqüentemente as indústrias de pescado possuem funcionários efetivos, ou permanentes, e funcionários temporários, contratados para o período de safra. No setor de produção e da manutenção, a maioria dos funcionários assina um contrato permanente (74\% e 88\%), e quase todos trabalham com carteira assinada ( $97 \%$ e 96\%). Os funcionários permanentes trabalham em média dois a quatro anos na empresa atual, e poucos mudaram de função na empresa. Mesmo assim, observa-se que entre 3\% e 4\% ainda não têm sua carteira de trabalho assinada.

Os empregados temporários, do setor de produção e manutenção, correspondem a 26\% (produção) e 12\% (manutenção) do total de funcionários da empresa. Dos funcionários temporários, apenas 40\% do setor de produção e $67 \%$ do setor de manutenção possuem carteira assinada. No entanto, o tempo médio de trabalho para esses funcionários temporários na empresa é de aproximadamente 10 meses, considerado um período bastante alto para atividades de prestação de serviços sem vínculo trabalhista com a empresa contratante. Geralmente, o funcionário 
temporário não exerce outra função na empresa além daquela para a qual foi contratado (Tabela 4).

Tabela 4: Histórico de trabalho dos funcionários da produção e manutenção na empresa atual da indústria pesqueira, Pará e Amazonas.

\begin{tabular}{lcc}
\hline & \multicolumn{2}{c}{$\begin{array}{c}\text { Hanutençāo de } \\
\text { Produçāo máquinas e limpeza }\end{array}$} \\
\hline Contrato de trabalho & & $12 \%$ \\
Funcionários temporários & $26 \%$ & $88 \%$ \\
Funcionários permanentes & $74 \%$ & $67 \%$ \\
Funcionário temporário com carteira assinada & $40 \%$ & $96 \%$ \\
Funcionário permanente com carteira assinada & $97 \%$ & \\
Tempo na empresa dos funcionários & & 5 \\
permanentes & & 4 \\
Média de tempo na empresa (ano) & 4 & $25 \%$ \\
Média de tempo na funçāo atual (ano) & 3 \\
Funcionários que mudaram de funçāo & $27 \%$ & $75 \%$ \\
Funcionários que permanecem na mesma funçāo & $73 \%$ & \\
Tempo na empresa dos funcionários & & 10 \\
temporários & & 10 \\
Média de tempo na empresa (mês) & 10 & $25 \%$ \\
Média de tempo na funçāo atual (mês) & 6 & $75 \%$ \\
Funcionários que mudaram de funçāo & $6 \%$ & \\
Funcionários que permanecem na mesma funçāo & $94 \%$ &
\end{tabular}

Os funcionários da produção, permanentes e temporários, exercem principalmente a função de auxiliar de produção e são responsáveis pela recepção, pela seleção e pela filetagem do pescado (71\% e 74\%) e também pela embalagem do produto (16\% e 18\%). Os funcionários do setor de manutenção de máquinas e limpeza, permanentes ou temporários, são principalmente faxineiros (46\% e 33\%), cozinheiros (67\%) e, em menor escala, mecânicos, auxiliares de serviços gerais e eletricistas, respectivamente (Tabela 5). 
Lucilene Amaral / Oriana Almeida / Sérgio Rivero

Tabela 5: Função atual dos funcionários da produção e manutenção da indústria pesqueira, Pará e Amazonas.

\begin{tabular}{lcc}
\hline \multicolumn{3}{c}{ Principais funções } \\
\hline \multicolumn{1}{c}{ Funcionários da produção } & $\begin{array}{c}\text { Funcionários da manutenção } \\
\text { Permanentes }\end{array}$ & $46 \%$ \\
Auxiliar de produção & $71 \%$ Faxineiro & $15 \%$ \\
Embalador & $16 \%$ Mecânico & $15 \%$ \\
Encarregado de setor & $9 \%$ Serviços gerais \\
Cozinheiro & $2 \%$ Eletricista & $12 \%$ \\
Auxiliar de encarregado & $2 \%$ Operador de máquina & $8 \%$ \\
& $\quad$ Segurança & $4 \%$ \\
Temporários & $\quad$ Temporários \\
Auxiliar de produção & $74 \%$ Cozinheiro & \\
Embalador & $18 \%$ Faxineiro & $67 \%$ \\
Encarregado de setor & $6 \%$ & $33 \%$ \\
Auxiliar de encarregado & $2 \%$ & \\
\hline
\end{tabular}

Embora o salário dos funcionários da administração seja maior, o histórico de trabalho é similar. Dos funcionários da administração, praticamente a metade começou a trabalhar entre 10 e 18 anos, enquanto outros iniciaram os trabalhos após 18 anos. Apenas uma minoria (4\%) começou a trabalhar antes dos 10 anos. No primeiro emprego, a principal função exercida pelos funcionários da administração era a de auxiliar de escritório (50\%), seguida de serviços domésticos e outras atividades, como vendedor, vigia ou auxiliar de produção.

Assim como os funcionários permanentes da produção e da manutenção, a maioria dos funcionários da administração possui carteira assinada (96\%). O contrato de trabalho é por tempo indeterminado, e apenas 4\% apresenta contrato temporário e não possui carteira assinada.

Os funcionários da administração trabalham, em média, há seis anos na empresa, diferentemente dos funcionários da produção, cuja média é de dois anos. Os funcionários da administração são principalmente assistentes administrativos (39\%), chefes de departamento (22\%), auxiliares de contabilidade (13\%), recepcionistas (9\%) e ainda, em menor escala, secretárias, tesoureiros e técnicos em enfermagem. Os funcionários das empresas de pescado não mudam muito de função dentro da empresa. Nos três setores, cerca de 70\% dos funcionários sempre exerceram a mesma função. O restante já exerceu outra atividade dentro da empresa e está pelo menos há três anos na função atual. 


\section{Expectativas dos funcionários}

A maior expectativa dos funcionários da produção e da manutenção das indústrias de pescado é em relação à moradia. Os funcionários desses setores anseiam por comprar, reformar ou construir a casa própria nos próximos dois anos (66\%). Uma porcentagem menor (12\%) deseja adquirir móveis ou eletrodomésticos. Poucos funcionários afirmaram ter como expectativa futura investir em trabalho autônomo, comprar um veículo, investir na educação dos filhos ou, ainda, concluir os próprios estudos.

Por outro lado, os funcionários da administração têm suas expectativas mais direcionadas para a reforma da casa e aquisição de bens como carros, motos, móveis ou eletrodomésticos. Os funcionários de setor administrativo estão mais propensos a investir em educação (própria ou dos filhos), pagar dívidas ou abrir uma caderneta de poupança.

\section{Dificuldades enfrentadas pelos funcionários}

Os funcionários dizem enfrentar várias dificuldades, principalmente em relação às suas atividades na empresa, aos cursos de treinamento recebidos, a acidentes e doenças de trabalho.

Em relação os cursos de treinamento, somente 18\% dos funcionários temporários e 48\% dos funcionários permanentes afirmaram ter recebido treinamento. Desse total, apenas 9\% afirmam que enfrentaram dificuldade no treinamento. Alguns consideraram o conteúdo complexo, outros tiveram dificuldades em identificar as espécies de pescado. Alguns tiveram problemas de logística, como dificuldade de deslocamento para o local ou dificuldade visual para assistir aos cursos. Os demais funcionários que receberam treinamento não sentiram dificuldade durante o curso.

A maioria dos funcionários, entretanto, acha que os cursos são acessíveis e adequados (80\%), e 8\% disseram que deveriam ser mais freqüentes. O restante acha que a qualidade dos cursos poderia ser melhorada com a utilização de uma linguagem mais simples, com a realização dentro da própria empresa ou uma carga horária maior.

Embora a maioria dos funcionários da produção e da manutenção não tenha recebido nenhum treinamento, grande parte afirma não sentir dificuldades para exercer suas atividades. Isso se deve ao fato de muitos funcionários da indústria de pesca atuarem há vários anos no setor, passando por empresas diferentes ou sendo recontratados pela mesma empresa em diferentes safras. Somente 17\% dos funcionários 
Lucilene Amaral / Oriana Almeida / Sérgio Rivero

permanentes e 5\% dos funcionários temporários têm alguma dificuldade para exercer suas funções.

Entre os funcionários permanentes que sentem dificuldades no trabalho, os principais problemas mencionados são: o uso do fardamento (23\%) - alguns funcionários não se sentem confortáveis com o uso dos equipamentos necessários, outros, apesar de utilizá-los, afirmam que os equipamentos não são adequados -, a falta de transporte de casa para o trabalho (23\%) e o relacionamento com os colegas (18\%). Outros problemas menos citados foram a falta de material de trabalho, principalmente nos setores de limpeza e de embalagem, a jornada diária longa de trabalho, a pouca quantidade de alimento oferecido no refeitório e ainda o longo período de trabalho em pé. Alguns funcionários do setor de produção também mencionaram como problema a grande quantidade de peso a ser carregado.

Várias sugestões foram apresentadas pelos funcionários da produção e da manutenção para que a empresa melhore seu serviço. Alguns acham que a empresa deveria comprar equipamentos e fardamentos novos (11\%), outros entendem que a empresa deveria conceder aumento salarial (10\%), outros ainda gostariam que a empresa reduzisse a jornada de trabalho (7\%) e oferecesse mais cursos de capacitação e especialização (7\%). Algumas sugestões ainda foram citadas em menor proporção, como a solicitação do pagamento dos salários em dia, a assinatura da carteira para todos os funcionários e a melhor distribuição de funções na empresa.

Ainda que as empresas priorizem os cursos voltados para o setor de produção, a maioria dos funcionários da administração (52\%) já recebeu algum treinamento específico para o setor em que trabalha, promovido pela empresa ou por outras instituições. Os cursos foram na área de contabilidade, finanças, departamento de pessoal e informática. Nenhuma dificuldade específica foi mencionada por aqueles que receberam treinamento.

Em relação ao trabalho que executam, 78\% dos funcionários do setor da administração não sentem dificuldades no trabalho. Dos funcionários que sentem alguma dificuldade, 40\% dizem que falta especialização para exercer a função. Entre as sugestões de melhoria, 35\% dizem-se satisfeitos com a empresa, 17\% acham que a empresa deveria melhorar os equipamentos do setor de administração, 13\% gostariam que o ambiente de trabalho fosse maior; alguns destacaram mais cursos de capacitação (13\%) e 9\% sugeriram que houvesse mais reuniões dos funcionários com a gerência e que pudessem receber aumento salarial. 
Poucos funcionários mencionaram a ocorrência de acidentes de trabalho. No entanto, 18\% dos funcionários da produção já sofreram algum acidente de trabalho (13\% dos funcionários permanentes e 5\% dos funcionários temporários). Os principais acidentes ocorridos foram cortes nos dedos, cortes nas pernas, queimaduras e outros menores, ocorridos principalmente no setor de produção. Dos que sofreram acidentes, saíram de licença e receberam benefício do INSS, 60\% trabalhavam no setor de produção. Apenas 1\% dos funcionários da administração e 3\% dos funcionários da manutenção sofreram acidentes de trabalho (Tabela 6).

Tabela 6: Funcionários que sofreram acidentes de trabalho por setor de trabalho e principais tipos de acidentes sofridos, indústria pesqueira, Pará e Amazonas.

\begin{tabular}{lc}
\hline & \% \\
\hline Funcionários que sofreram acidentes & 22 \\
Da adminis tração & 1 \\
Da manutenção de máquinas & 3 \\
Da produçáo & 18 \\
Funcionários acidentados que receberam & \\
benefício do INSS & $\mathbf{5}$ \\
Da administração & - \\
Da manutenção de máquinas & 40 \\
Da produção & 60 \\
Principais tipos de acidentes sofridos & \\
Cortes de dedo & 47 \\
Cortes na perna & 12 \\
Queimaduras & 12 \\
Outros & 29 \\
\hline
\end{tabular}

Do total de funcionários, 13\% afirmaram que já contraíram alguma doença no ambiente de trabalho. A ocorrência de casos de doenças é mais freqüente no setor da produção, onde 11\% dos funcionários já apresentaram algum tipo de doença. As principais doenças adquiridas foram: respiratórias (38\%), como gripes, pneumonia e tosse; dores no corpo ou na cabeça (17\%), provocadas pela exposição prolongada do funcionário às câmaras frigoríficas e aos salões climatizados; infecções urinárias ou intestinais (13\%); viroses (8\%) e reumatismo (8\%). Ainda em menor escala, outros funcionários afirmaram que tiveram perda de audição, desgaste físico, alergias às luvas usadas e problemas na coluna - devido ao excesso de peso que carregam (Tabela 7). 
Lucilene Amaral / Oriana Almeida / Sérgio Rivero

Tabela 7: Funcionários que adquiriram doenças de trabalho por setor e principais doenças adquiridas, indústria pesqueira, Pará e Amazonas.

\begin{tabular}{lc}
\hline Funcionários que tiveram doença de & \% \\
\hline Produção & 11 \\
Adminis tração & 1 \\
Marutenção de máquinas e limpeza & 1 \\
Funcionários que não tiveram doenças & 87 \\
Principais doenças adquiridas & \\
Problemas respiratórios & 38 \\
Dores no corpo & 17 \\
Infecções diversas & 13 \\
Viroses & 8 \\
Reumatismo & 8 \\
Perda de audição & 4 \\
Desgaste físico & 4 \\
Alergias & 4 \\
Problemas na coluna & 4 \\
\hline
\end{tabular}

\section{Renda e características dos funcionários}

A correlação de Pearson foi utilizada para explorar a relação entre as características dos funcionários e os indicadores de renda. A correlação entre variáveis categóricas e quantitativas também foi utilizada para analisar os dados. O resultado demonstrou baixo nível de correlação entre as variáveis, quase nenhuma correlação tendo sido maior que 0,50. De maneira geral, variáveis relativas ao patrimônio da família, como possuir $\mathrm{TV}$, rádio, intenção de aumentar o tamanho da casa, são correlatas. As despesas da família também estão correlacionadas significativa $(p<0,01)$ e positivamente entre si, mas apresentam baixa correlação (raramente acima de 0,5).

A idade do funcionário está correlacionada de forma positiva com a posse da casa própria e com o tempo de trabalho na empresa. Curiosamente, há pouca relação entre essas variáveis e o fato de o funcionário ter um contrato de longo prazo na empresa. Não há relação positiva ou negativa, por exemplo, entre o fato de o funcionário ser permanente e o seu patrimônio, nem com o valor de suas despesas mensais. Outro dado curioso é a relação negativa significativa $(-0,532)$ entre o fato de o funcionário ser permanente e o salário.

A idade está relacionada positivamente ao fato de o funcionário ter casa própria, de forma que, quanto mais velha a pessoa, maior a 
possibilidade de adquirir casa própria com o tempo de trabalho na empresa. O grau de instrução está relacionado negativamente à idade indicando que, quanto mais velho, menor o nível de instrução -, assim como ao número de filhos e ao fato de possuir casa própria. O grau de instrução também está vinculado negativamente ao fato de o funcionário pertencer à administração.

A correlação foi significativa e positiva entre o fato de ser funcionário da administração e as variáveis ligadas ao patrimônio do indivíduo e à renda. Isso decorre da existência de uma correlação positiva significativa $(0,471)$ entre pessoas do setor da administração e o salário recebido, o que mostra que as pessoas que trabalham na administração recebem salário maior.

\section{CONCLUSÃO}

A mão-de-obra na indústria pesqueira apresenta baixa qualificação profissional, embora a maioria dos funcionários tenha iniciado suas atividades ainda jovens e tenha passado por atividades diversificadas, principalmente os homens. As mulheres, no entanto, ocupam a maioria dos postos de emprego nas indústrias de pescado. Geralmente com experiência em trabalhos domésticos, as mulheres são consideradas pelos empregadores como mais hábeis para o trabalho de processamento e filetagem do pescado. Elas também estão presentes no setor administrativo e de limpeza das empresas, enquanto os homens são mais numerosos nos postos que exigem maior esforço físico.

Do ponto de vista da empresa, a maior dificuldade com a mão-deobra está concentrada no setor de produção. Funcionários com baixa qualificação e com difícil adequação aos padrões de higiene são os principais problemas apontados pelas gerências. Parte do problema de treinamento está ligada ao sistema de contratação temporária: 44\% das empresas utilizam o sistema rotativo de mão-de-obra, contratando funcionários temporários para o período de safra e demitindo-os depois. Em geral, os funcionários temporários correspondem a 26\% do total de funcionários do setor de produção. Muitos deles não possuem carteira assinada e chegam a trabalhar até 10 meses seguidos na mesma empresa.

Os cursos de treinamento são vistos pelas empresas e pelos empregados como algo importante para o setor. No entanto, as empresas com registro no Serviço de Inspeção Federal (SIF) têm maior preocupação com o treinamento da mão-de-obra, uma vez que precisam cumprir os padrões de qualidade para atender ao mercado consumidor. Por isso, 
Lucilene Amaral / Oriana Almeida / Sérgio Rivero

muitas têm investido em treinamentos direcionados ao setor de produção, criando auditórios destinados à realização de cursos e contratando funcionários qualificados para assumir o controle de qualidade. Apesar da preocupação da empresa em promover os cursos, poucos funcionários do setor de produção receberam treinamento (18\% dos funcionários temporários e 48\% dos funcionários permanentes).

Do total de funcionários entrevistados, 22\% afirmaram que já sofreram algum tipo de acidente no trabalho ou adquiriram alguma doença. Pequenas lesões, como cortes e queimaduras, são bastante freqüentes entre os funcionários do setor de processamento do pescado, mas esses acidentes muitas vezes são vistos como casos irrelevantes pelos empregadores e até mesmo pelos empregados. Só os casos de maior gravidade chegam ao conhecimento da gerência, que encaminha os funcionários atingidos para tratamento. Da mesma forma, males como dores na coluna ou nas pernas, também relatados por alguns funcionários, raramente são considerados como doença adquirida no trabalho e poucos funcionários interrompem suas atividades para buscar tratamento médico.

Nas empresas onde há maior comunicação entre funcionários e gerência, foi identificado um nível maior de satisfação dos empregados. Em muitas empresas, as reuniões ocorrem somente quando há um problema específico a ser resolvido. Na maioria das empresas, os funcionários não expressam suas dificuldades e problemas, assim como desconhecem seus direitos. Em vários casos, a boa comunicação entre funcionário e gerência, por meio de reuniões periódicas, promove grande nível de satisfação nos empregados. As empresas que fazem reuniões semanais ou mensais para discutir os problemas, ou promovem atividades recreativas, cursos de treinamento e capacitação, possuem funcionários mais satisfeitos com o trabalho.

Por fim, as empresas que mantêm um quadro fixo de funcionários afirmam que têm menos desperdício de matéria-prima, maior rendimento dos empregados e, conseqüentemente, maior produtividade. Também afirmam ter funcionários mais treinados e adaptados aos padrões de higiene exigidos. A contratação de empregados permanentes parece ser positiva tanto para os funcionários quanto para as empresas, mas exige que a empresa tenha uma estratégia mais ampla para o abastecimento de pescado na entressafra, de forma que seja possível manter a mão-de-obra contratada no período da safra. 


\section{REFERÊNCIAS}

ALMEIDA, O. T. ; LORENZEN, Kai ; MCGRATH, David . Commercial fishing sector in the regional economy of the brazilian Amazon. In: R. Welcomme; T. Peter. (Org.). Proceedings of the Second International Symposium on the Management of Large Rivers for Fisheries. 1 ed. Bangkok: FAO-Regional Office for Asia and the Pacific/RAP Pulication, v. 2, p. 15-24. 2004.

BARTHEM, R. A pesca comercial no Médio Solimões e sua interação com a Reserva de Desenvolvimento Sustentável Mamirauá. In: QUEIROZ, H.; CRAMPTON, W. Estratégias para manejo de recursos pesqueiros em Mamirauá. Brasília, DF: Sociedade Civil do MamirauáCNPq. p. 72-107. 1999.

CABRAL, W.; ALMEIDA, O. T. Avaliação do mercado da indústria pesqueira na Amazônia. In: ALMEIDA, O. (Org.). A indústria pesqueira na Amazônia. Manaus: ProVárzea/IBAMA, p. 17-40. 2006.

CERDEIRA, R. G. P.; RUFFINO, M. L.; ISAAC, V. J. Consumo de pescado e outros alimentos pela população ribeirinha do Lago Grande de Monte Alegre, PA - Brasil. Acta Amazônica, Manaus, v. 27, n. 3, p. 213-227, 1997.

IBAMA (2001) Relatório estatístico da pesca, 2000. Brasília: IBAMA, 2001.

MCGRATH, D.; SILVA, U.; CROSSA, M. N. A traditional floodplain fishery of the lower Amazon river, Brazil. NAGA p. 4-11, Jan./Mar. 1998.

Ministério do Desenvolvimento, Indústria e Comércio. 2003. Sistema de Análise das Informações de Comércio Exterior da Secretaria de Comércio Exterior - Secex. ALICEWEB. Disponível em: http:// aliceweb.mdic.gov.br. Acesso em; 25 jun. 2006.

OLIVEIRA, A.; CUNHA, L. Community management of the floodplain lakes of the middle Solimões River, Amazonas State, Brazil: a model of preservation in transformation. In: BIENNIAL CONFERENCE OF THE INTERNATIONAL ASSOCIATION FOR THE STUDY OF COMMON 
Lucilene Amaral / Oriana Almeida / Sérgio Rivero

PROPERTY (IASCP), 8. Proceedings... 2000. 20 p. Disponível em: $<$ http://dlc.dlib.indiana.edu/archive/00000319/>. Acesso em: 27.07.2007

SENA, A. L. Trabalho e trabalhadores da pesca industrial face à metamorfose do capital. Belém, NAEA. p. 390, 2006.

SMITH, R. Community-based resource control and management in the Amazonia: a research initiative to identify conditioning factor for positive outcomes. In: BIENNIAL CONFERENCE OF THE INTERNATIONAL ASSOCIATION FOR THE STUDY OF COMMON PROPERTY (IASCP), 8. Proceedings... 2000. 20 p. Disponível em: < http://dlc.dlib.indiana.edu/ archive/00000352/ > . Acesso em: 27.07.2006.

\section{Agradecimentos}

Gostaríamos de agradecer à gerência e aos funcionários de todos os frigoríficos que aceitaram que a pesquisa fosse realizada e nos concederam as entrevistas. Agradecemos ao apoio de Ivanildo Pontes e de Rigoberto Pontes. Agradecemos a José Vicente Ribeiro pela ajuda na elaboração e no teste dos questionários na empresa em que trabalha. Agradecemos a Nadson Oliveira, Cristiane e Helcemir Amaral pela ajuda na coleta de dados. Agradecemos a Ivoneide Teixeira, do IPAM, por elaborar o banco de dados e a Fátima Fernandes por digitá-los. Agradecemos o apoio financeiro do IBAMA/Provárzea, DFID, GTZ, KFW, Banco Mundial, PPG7, PNUD, IPAM e Moore Foundation para a realização deste trabalho. 